\section{Genuine and natural: the opinion of teen consumers}

\author{
Stefania Balzan, ${ }^{1}$ Luca Fasolato, ${ }^{1}$ \\ Barbara Cardazzo, ${ }^{1}$ Cristiana Penon, ${ }^{2}$ \\ Enrico Novelli ${ }^{1}$
}

${ }^{1}$ Department of Comparative

Biomedicine and Food Science, University of Padua, Legnaro (PD); ${ }^{2}$ Hygiene of Food of Animal Origin Service, Local Health Unit 8 Berica, Vicenza, Italy

\begin{abstract}
Food packaging frequently reports the terms natural, $100 \%$ natural or similar. Often these indications induce consumers to purchase those products that are considered healthier and fresher. The overall goal of this study was to assess what teen consumers perceive to be genuine and natural foods. A questionnaire was distributed to the students of some high schools (lyceum, technical and professional institutes). It was completed by 349 females and 314 males, with an average age of 17.6 years. Respondents are quite interested in the information on recipes, diet, beauty and food safety; websites were important information retrieval tools. Genuine food is defined mainly as fruits and vegetables, home-made and salubrious, with less or without fat and that is good for health. Meanwhile, natural is demarcated primarily by the absence of additives and manipulation or treatments (negative impact). Also fruits and vegetables and organic production are associated to natural. The existence of a natural food preference is well described and the presence on food label may cause a wrong perception of healthfulness.
\end{abstract}

\section{Introduction}

On food labels it is very common to find terms as natural, 100\% natural, genuine, etc. Moreover, the appeal to the nature and genuineness is common even in advertising.

But what do these terms mean? If the term natural is more familiar in everyday language, the same cannot be stated for the word genuine.

Dictionary defines genuine as: not fake or counterfeit, original, real, authentic or sincere, pure, not artefact (Collins, 2016). Specialised journalists, producer organisations and legal experts are questioning the use of these terms on the label in order to avoid false or misleading claims (Coldiretti, 2013; Costantino, 2014; Bottaro, 2015). In Italy the term natural is associated to water (natural mineral water, 80/777/EEC; European Commission, 1980) or certain food. For example it is very common tonno al naturale (tuna chunks in brine) where natural [Art. 4, Council Regulation (EEC) No 1536/92; European Commission, 1992], indicated a product with the natural juice (the liquid exuding from the fish during cooking), a saline solution or water, possibly with the addition of herbs, spices or natural flavorings as defined in 88/388/EEC Council Directive. Frequently this term is also referred to flavoring where, according to Regulation (EC) No 1334/2008 (European Commission, 2008), The term natural may only be used in combination with a reference to a food, food category or a vegetable or animal flavoring source if the flavoring component has been obtained exclusively or by at least $95 \%$ by w/w from the source material referred to or when a food naturally meets the condition(s) laid down in the Annex of Regulation (EC) No 1924/2006 (European Commission, 2006) for the use of a nutritional claim. The Food Standard Agency (2008) has provided criteria for the use of several terms in food labelling and, about natural reported (literally cited): Natural means essentially that the product is comprised of natural ingredients, e.g. ingredients produced by nature, not the work of man or interfered with man, clarifying a number of cases in which the term can be used (dairy product, bottle water, health and nutrition claims, and other specific situations). As a result of three Citizen petitions and other requests from some Federal courts regarding food products containing ingredients produced using genetic engineering or foods containing high fructose corn syrup and claims, the US FDA requests comments on use of the term natural on food labeling (FDA, 2016). As literally reported in their website, The FDA has considered the term natural to mean that nothing artificial or synthetic (including all color additives regardless of source) has been included in, or has been added to, a food that would not normally be expected to be in that food. However, this policy was not intended to address food production methods, such as the use of pesticides, nor did it explicitly address food processing or manufacturing methods, such as thermal technologies, pasteurization, or irradiation. The FDA also did not consider whether the term natural should describe any nutritional or other health benefit.

Often the term natural persuade consumers to buy, convinced to choose a healthier product, or more fresh, in general,
Correspondence: Stefania Balzan, Department of Comparative Biomedicine and Food Science, University of Padova, Viale dell'università 16, 35020 Legnaro $(\mathrm{PD})$.

Tel. +39.049.8272846 - Fax: +39.049.8272604.

E-mail: stefania.balzan@unipd.it

Key words: Knowledge; Food; Culture; Youngsters; Perception.

Conflict of interest: the authors declare no potential conflict of interest.

Acknowledgments: the authors gratefully acknowledge all the teachers who kindly permitted the questionnaires to be distributed in their classes. Authors wish to thank Servizio di Promozione ed Educazione alla Salute (SPES) - ULSS 8 Berica for their support.

Received for publication: 20 July 2016. Revision received: 12 January 2017. Accepted for publication: 13 January 2017.

This work is licensed under a Creative Commons Attribution-NonCommercial 4.0 International License (CC BY-NC 4.0).

(C) Copyright S. Balzan et al., 2017

Licensee PAGEPress, Italy

Italian Journal of Food Safety 2017; 6:6183

doi:10.4081/iifs.2017.6183

with particular characteristics. Studies have showed that frequently people prefer natural things to those that have been produced with human intervention and it is particularly obvious for food (Rozin et al., 2004) where consumers select a natural to the corresponding commercial product. For the phenomenon called natural preference Rozin (2005) identified: i) instrumental (healthier, more appealing to the senses, eco-friendly), and ii) ideational reasons (better, right, ethical, more aesthetic). Evans et al. (2010) noted a pressure on producers to eliminate everything that might be perceived to be unnatural but a legislative gap (especially in Italy) induces manufacturers to use the term inappropriately.

In the present study, we explore the meaning given by teenager to the natural and genuine concepts associated with commonly eaten foods.

\section{Materials and Methods}

A questionnaire was distributed to the students of some high schools: lyceum (L) n.153, technical institute (T) n.172, professional institute $(\mathrm{P}) \mathrm{n} .338$, in the territory of Local Health Unit 6, Vicenza, Italy.

Regarding schools, Lyceum include 
Scientific high school, Language High School, Human science high school, while Technical institute consist of State industrial and technical institute, Technical and commercial institute. Finally, Professional institute comprise Technical service providers in tourism, Technical assistance and maintain, Hairdressing school, Hospitality institute.

Participation was anonymous. The questionnaire was completed by 349 females (F) and 314 males (M) with an average age of 17.6 years (males: $17.7 \pm 1.1$; females: $17.5 \pm 1.1$ ).

In addition to standard demographic items first section of questionnaire contained a list of queries to assess students knowledge on food risk (data not reported in this paper). In the second part participants were asked to indicate an open-ended definition of genuine food and natural one; moreover students were asked to freely associate three words (nouns, adjectives, verbs) to natural food. In addition Likert scales, $1=$ not interested to never to $5=$ very interesting and $1=$ never to $4=$ always, were used for evaluate their interest about food information and resource information questions, respectively. Also some questions about choice and concern about food were asked.

A substantive analysis of the free associations and of the open-ended definition of genuine and natural was provided. For individual items, any words that are diverse forms of the same word (e.g. vegetables, lettuce), or words that are synonyms (e.g., in Italian sano e salubre that meaning healthy and salubrious) were grouped together. The most frequent associations to genuine and natural are scheduled in order of frequency (Rozin et al., 2004).

Descriptive statistics, such as frequencies, percent, and crosstabs, were calculated using the SPSS statistical programme, version 22.0 (SPSS, 2013). Chi-square statistics were performed to determine statistical differences. Significant results were reported at the $\mathrm{P}<0.05$ level. The transcripts were analysed with NVivo software (QSR, 2012).

\section{Results and Discussion}

Table 1 shows attitudes about food information and information sources used by teenagers and Table 2 reported data shared by schools. In general, students said they were enough interested to recipes $(41.4 \%)$, beauty $(38.3 \%)$, health and nutrition $(43.5 \%)$, and food safety (45.6\%). When evaluated by sex, about food safety students have declared to be enough interested (both sex). Females were more interested than males with regard to health and nutrition $(\mathrm{P}<0.05)$ and beauty $(\mathrm{P}<0.001)$. Students of professional schools are very interested in the recipes $(\mathrm{P}<0.05)$ while lyceum students are more interested in health and diet $(\mathrm{P}<0.05)$. Unlike the newspaper, websites was an important information retrieval tool and used more than social media.
Schoolwork, social life/relaxation activities, current information, personal improvement, and job information are the information needs of youth (Agosto and Hughes-Hassell, 2005). Authors reported that teenagers recognised people as their preferred information source. Telephones, televisions, computers, and radios are favored media that use before using newspapers, and magazines. Burke et al. (2016) reported that preferred information source of 19-29 year olds were family/friends $(72.3 \%)$, the Internet $(68.4 \%)$, and federal government food safety websites $(34.2 \%)$. Magazines and newspapers were mentioned by 11.4 and $10.4 \%$ of respondents. The different interests between males and females were expected and the great interest in the recipes can be explained by the presence of many students of hospitality institute. Wartella et al. (2015) noted that the teens are primarily looking for health information on everyday topics such as exercise and nutrition, anxiety, sexually transmitted infections, depression and sleep. The great majority of teens also go to the Internet for health information that should be accurate, appropriate, and easily accessible.

When interviewed about how changes their attitude towards a food that they consume but on which problems were encountered [fraud, dioxin, genetically modified organism (GMO), etc.], data reported that $45.9 \%$ do not consume more these food, $25.5 \%$ do not consume only during the emergency period, $7.4 \%$ not change their habitude and, $21.3 \%$ are concerned but do

Table 1. Consumers' interest in food and food safety (teenagers).

\begin{tabular}{|c|c|c|c|c|c|c|c|}
\hline & & & Information & out food & & & \\
\hline & Sex & Not interested & Little interested & Indifferent & Quite interested & Very interested & $\mathbf{P}$ \\
\hline Recipes & $\mathrm{F}$ & 4.3 & 10.0 & 17.2 & 47.3 & 21.2 & 0.05 \\
\hline & M & 9.6 & 14.7 & 21.8 & 34.6 & 19.2 & \\
\hline Beauty & $\mathrm{F}$ & 1.7 & 5.7 & 26.4 & 39.4 & 26.7 & 0.001 \\
\hline & M & 9.9 & 11.5 & 29.7 & 37.4 & 11.5 & \\
\hline Health and nutrition & $\mathrm{F}$ & 0.6 & 3.7 & 7.4 & 45.3 & 43.0 & 0.001 \\
\hline & M & 5.1 & 7.6 & 17.8 & 41.7 & 27.7 & \\
\hline Food safety & $\mathrm{F}$ & 1.4 & 4.0 & 11.8 & 44.1 & 38.6 & ns \\
\hline & M & 4.8 & 4.5 & 12.2 & 48.4 & 30.1 & \\
\hline & & & Sources of $\mathrm{i}$ & rmation & & & \\
\hline & Sex & Never & Sometimes & Often & Always & $\mathbf{P}$ & \\
\hline Newspaper and magazines & $\mathrm{F}$ & 24.1 & 52.4 & 19.5 & 4.0 & 0.001 & \\
\hline & M & 42.2 & 45.4 & 9.9 & 2.6 & & \\
\hline Websites & $\mathrm{F}$ & 8.0 & 31.9 & 42.2 & 17.5 & 0.05 & \\
\hline & M & 18.8 & 31.9 & 36.7 & 12.5 & & \\
\hline Social media & $\mathrm{F}$ & 35.5 & 38.1 & 20.1 & 6.3 & 0.001 & \\
\hline & M & 54.0 & 26.2 & 14.1 & 5.4 & & \\
\hline TV & $\mathrm{F}$ & 19.0 & 50.7 & 24.8 & 5.5 & ns & \\
\hline & M & 25.9 & 42.5 & 25.2 & 6.4 & & \\
\hline
\end{tabular}

F, female; M, male; ns, not significant. Values are reported as percentages. 
nothing. Data shared by school were similar to the general trends without statistical difference. Obviously respondents tend to adopt one action to reduce perceived risk in a purchase. Yeung and Morris (2001) observed that the greater the perception of risk, the greater is the probable action to reduce the risk. Food shopping is usually done by one person for the entire household and because of the young age it is likely that respondents are not involved in purchases.

About question What grabs your attention in the choice of a food? (it was not intentionally added I like), the choice is determined by beneficial effects to health and growth (F: 32.5\%, M: 25.1\%), packaging (F: $17.4 \%, \mathrm{M}: 19.1 \%$ ), availability at school, in sports or recreational settings ( $\mathrm{F}$ : $17.1 \%$, M: $15.4 \%$ ), advertising ( $\mathrm{F}: 14.5 \%$, $\mathrm{M}: 11.7 \%$ ), similarity to that done in house (F: 13.6\%, M: 20.4\%) and, choice from friends (F: 4.6\%, M: 8.0\%). No statistically difference were found in gender for both these questions.

When data were considered by school (Table 2), the choice of a particular food $(\mathrm{P}<0.001)$ is determined by beneficial effects to health and growth (L: $40.3 \%$, P: 25.2\%; T: 26.1\%), packaging (L: $15.4 \%$, P:
$20.4 \%$, T: $17.4 \%$ ) availability at school, in sports or recreational settings (L: $8.1 \%$, P: 16.9\%, T: $21.7 \%$ ), advertising (L: $15.4 \%$, P: $13.7 \%$, T: $10.3 \%$ ), similarity to that done in house (L: $18.1 \%$, P: $16.9 \%$, T: $15.8 \%$ ) and, choice from friends (L: $2.7 \%, \mathrm{P}: 6.4 \%$, T: $8.7 \%$ ). Adolescents have several motivations for every food choice and these motivations may be in conflict at times. Frequently food was chosen for taste, familiarity or health and the conflict between different motives for choosing food (e.g., taste, familiarity, or health) is largely resolved by the personal choice rule (Contento et al., 2006).

Natural is a concept that includes economics and consumer law, trade and health affairs, and symbolic aspects. And its meaning evolves with time; natural product was synonymous with perishable and contamination until the end of $19^{\text {th }}$ century; afterwards preservatives and, in wider terms, food additives changed the notion of perishability with that of toxicity. So natural is set against to chemistry. Natural was also the link between a specific product and a given area (e.g. terroir); historically natural wine it was used to distinguish winemaker by wine retailer (Stanziani, 2008).
Tables 3 and 4 reported the meaning given to genuine and natural terms by teens. We developed a coding scheme for the definitions of genuine and natural. It is evident that in part overlap.

Students have more difficult to give meaning of genuine food. They described as genuine, fruits and vegetables, homemade, salubrious foods, with less or without fat and that are good for health. Instead they indicated as natural vegetables, organic, salubrious food, absolutely without treatments or modifications (and when necessary should be minimal). Definition was very similar between males and females. No significant differences were observed between schools. Often there is a very precise use of certain technical terms probable due to the subjects studied. Also other authors (Rozin et al., 2012) have observed uniformity across gender and occupations.

Concerns over food additives, ingredients and methods of production obtain considerable media attention and consumers' interest. Consumers seem to be more aware of the ingredients and appear to choose products without food additives. Evans et al. (2010) reported to be a tendency to generalise risk to many food ingredients or

Table 2. Consumers' interest in food and food safety (schools).

\begin{tabular}{|c|c|c|c|c|c|c|c|}
\hline & & & Information & lout food & & & \\
\hline & School & Not interested & Little interested & Indifferent & Quite interested & Very interested & $\mathbf{P}$ \\
\hline Recipes & $\mathrm{L}$ & 9.2 & 16.3 & 18.3 & 41.8 & 14.4 & 0.001 \\
\hline & $P$ & 5.3 & 7.4 & 17.6 & 41.5 & 28.2 & \\
\hline & $\mathrm{T}$ & 7.4 & 17.0 & 22.9 & 41.5 & 11.2 & \\
\hline Beauty & L & 7.2 & 11.1 & 22.9 & 37.9 & 20.9 & ns \\
\hline & $\mathrm{P}$ & 4.0 & 5.6 & 29.1 & 41.2 & 20.1 & \\
\hline & $\mathrm{T}$ & 6.9 & 11.7 & 29.8 & 34.0 & 17.6 & \\
\hline Health and nutrition & $\mathrm{L}$ & 3.3 & 3.9 & 9.2 & 43.1 & 40.5 & 0.05 \\
\hline & $P$ & 1.2 & 4.6 & 12.7 & 45.1 & 36.4 & \\
\hline & $\mathrm{T}$ & 4.8 & 9.0 & 14.3 & 41.3 & 30.7 & \\
\hline Food safety & L & 2.0 & 5.2 & 9.2 & 45.1 & 38.6 & 0.05 \\
\hline & $P$ & 2.8 & 2.2 & 10.3 & 46.1 & 38.6 & \\
\hline & $\mathrm{T}$ & 4.3 & 6.9 & 17.6 & 46.3 & 25.0 & \\
\hline & School & Never & Sometimes & Often & Always & $\mathbf{P}$ & \\
\hline Newspaper and magazines & $\mathrm{L}$ & 26.1 & 56.2 & 12.4 & 5.2 & 0.05 & \\
\hline & $\mathrm{P}$ & 30.7 & 48.9 & 17.3 & 3.1 & & \\
\hline & $\mathrm{T}$ & 41.8 & 42.9 & 13.3 & 2.2 & & \\
\hline Websites & L & 9.2 & 35.9 & 35.9 & 19.0 & 0.001 & \\
\hline & $P$ & 10.5 & 28.5 & 46.1 & 14.9 & & \\
\hline & $\mathrm{T}$ & 21.3 & 34.0 & 41.4 & 13.3 & & \\
\hline Social media & $\mathrm{L}$ & 46.4 & 29.4 & 19.0 & 5.2 & $\mathrm{~ns}$ & \\
\hline & $P$ & 39.3 & 37.5 & 17.0 & 6.2 & & \\
\hline & $\mathrm{T}$ & 50.8 & 27.0 & 15.9 & 6.3 & & \\
\hline TV & L & 25.5 & 52.3 & 20.3 & 2.0 & 0.05 & \\
\hline & $P$ & 18.0 & 46.0 & 28.0 & 8.1 & & \\
\hline & $\mathrm{T}$ & 26.6 & 44.7 & 23.4 & 5.3 & & \\
\hline
\end{tabular}

$\mathrm{L}$, lyceum; P, professional institute; T, technical institute; ns, not significant. Values are reported as percentages. 
processes but it is unknown as is wide concern.

When asked students to provide three words to define natural food, picture that emerges is of a product: salubrious (19.6\%), organic $(6 \%)$, genuine $(5.6 \%)$, fresh/ness $(4.8 \%)$, vegetables $(3.6 \%)$ and, fruits (3.2\%). Rozin et al. (2012) reported that most frequently specific features were no chemicals, no additives or alterations, and no contact with/intervention by humans. Follow by other themes: homemade, from a garden, simply, grown, healthy, and pure. These study involved European and American consumers and no-additives and no-processing categories were the most common mentioned in all countries.

Also in our work there was the dominance of negative terms (no, without, absence) and the absence of something is the concept of recurring. Positive affect includes food attribute (good, tasty, healthy, nice) and aspects of the environment (soil, spontaneous, without forcing). GMO was

Table 3. Categories and most frequent specific responses in defining genuine food (word frequency, weighted percentage).

\begin{tabular}{lc} 
& $\%$ \\
Food & \\
Fruits (fruits, apple, grapes) & 35.2 \\
Vegetables & \\
$\quad$ (vegetables, lettuce, tomato, etc.) & 35.2 \\
Meat & 4.3 \\
Fish & 4.3 \\
Food production & \\
Homemade (bread, pasta, etc.) & 40.0 \\
Organic & 20.0 \\
Vegetable garden & 13.3 \\
Respect of natural cycle & 4.4 \\
Farmers market (farm-to-table) & 4.4 \\
\hline Attribute & \\
Salubrious & 51.1 \\
Freshness & 11.7 \\
Natural & 7.5 \\
Good preservation & 5.4 \\
Safety & 4.3 \\
Inspected food & \\
(certification and inspection service) & 4.3 \\
Health & \\
Healthy (wellness, growth, etc.) & 58.8 \\
Not harmful & 37.4 \\
\hline Yes/no & \\
Without/less fat & \\
Without food preservatives & \\
Without coloring agent & 12.5 \\
No treatment/human intervention & 8.2 \\
Without chemicals substances & 6.7 \\
Rich in nutrient & \\
(vitamin, minerals, protein) & 6.7 \\
Without toxic substances & 5.9 \\
Without pesticides & 4.4 \\
\hline Only percentages z4 were reported. & \\
\end{tabular}

Table 4. Categories and most frequent specific responses in defining natural food (word frequency, weighted percentage).

\begin{tabular}{lc} 
Food & $\%$ \\
$\quad$ Vegetables & \\
$\quad$ (vegetables, lettuce, tomato, etc.) & 47.6 \\
$\quad$ Fruits & 38.1 \\
Food production & \\
Organic & 25.0 \\
Vegetable garden & 14.6 \\
From nature (spontaneous, from soil) & 12.5 \\
Homemade (bread, pasta, etc.) & 6.25 \\
Farmers market (farm-to-table) & 6.25 \\
\hline Attribute & \\
Salubrious & 55.6 \\
Freshness & 18.5 \\
Genuine & 11.1 \\
Good taste & 7.1 \\
Yes/no & \\
$\quad$ No treatment/human intervention & 29.0 \\
Without chemicals substances & 16.9 \\
Without food preservatives & 13.9 \\
Without coloring agent & 10.1 \\
Without pesticides & 9.9 \\
Without toxic substances & 6.2 \\
\hline Only percentages 24 were reported.
\end{tabular}

\section{Conclusions}

Our study has a number of limitations. Results are based on participants' pronouncements and should not be viewed as factually defined. The results cannot be extrapolated to the general population because of the small sample sizes, even if our findings in this study of attitudes to genuine and natural are confirmed by many outcomes obtained from other authors. Moreover, adult people should be considered. It is desirable that the use of the term natural on food packaging or in advertising should be regulated considering the real meaning attributed by the consumer in the case of food. Further investigation concerning the correlation between the characteristics of so-called natural products and consumers' expectations is required.

Only percentages $\geq 4$ were reported.

\section{References}

Agosto, DE, Hughes-Hassell, S, 2005. People, places, and questions: an investigation of the everyday life information-seeking behaviors of urban young adults. Libr Inform Sci Res 27:141-63.

Bottaro, G, 2015. Naturale, tradizionale, fatto a mano: tutte scritte che non significano niente. Le etichette ingannevoli per i consumatori sono colpa dei vuoti legislativi. Available from: http://www.ilfattoalimentare.it/etichette-ingannevoli-vuoti-legislativi.html

Burke T, Young I, Papadopoulos A, 2016. Assessing food safety knowledge and preferred information sources among 19e29 year olds. Food Control 69:83-9.

Coldiretti, 2013. "Naturale": gli USA regolano uso del termine. Available from: http://www.sicurezzaalimentare.it/qualita/Pagine $/ \%$ E2\% $\% 0 \% 9$ CNaturale $\%$ E2 $\% 80 \% 9$ DgliUSAregolanousodeltermin e.aspx

Collins, 2016. Available from: http://www.collinsdictionary.com/dictionary/english

Contento, IR, Williams, SS, Michela, JL, Franklin, AB, 2006. Understanding the food choice process of adolescents in the context of family and friends. J Adolescent Health 38:575-82.

Costantino L, 2014. L'utilizzo del termine "naturale" nell'etichettatura dei prodotti alimentari. Available from: http://www.rivistadirittoalimentare.it/ri vista/2014-03/COSTANTINO.pdf

European Commission, 1980. Council Directive of 15 July 1980 on the approximation of the laws of the Member States relating to the exploitation and marketing of natural mineral waters, 80/777/EEC. In: Official Journal, L 229, 30/08/1980, pp. 1-10.

European Commission, 1992. Council Regulation of 9 June 1992 laying down common marketing standards for preserved tuna and bonito, 1536/92/EEC. In: Official Journal, L 163, 17/06/1992, pp. 1-4.

European Commission, 2006. Regulation of the European parliament and of the council of 20 December 2006 on nutrition and health claims made on foods, 1924/2006/EC. In: Official Journal, L 404, 30/12/2006.

European Commission, 2008. Regulation of the European parliament and of the council of 16 December 2008 on flavourings and certain food ingredients with flavouring properties for use in and on foods and amending Council Regulation (EEC) No 1601/91, Regulations (EC) No 2232/96 and (EC) 
No 110/2008 and Directive 2000/13/EC, 1334/2008/EC. In: Official Journal, L 354, 31/12/2008.

Evans G, de Challemaison B, Cox DN, 2010. Consumers' ratings of the natural and unnatural qualities of foods. Appetite 54:557-63.

Food Standard Agency, 2008. Criteria for the use of the terms fresh, pure, natural etc. in food labelling. Available from: https://www.food.gov.uk/multimedia/cr iteriafoodlabelling.pdfUSA.

FDA, 2016. "Natural" on food labeling. The FDA requests comments on use of the term "natural" on food labeling. Food and Drug Administration, Silver Spring, MD, USA.
QSR, 2012. NVivo qualitative data analysis software, version 10. QSR International Pty Ltd., Doncaster, Australia.

Rozin, P, 2005. The meaning of "natural": process more important than content. Psychol Sci 16:652-8.

Rozin, P, Fischler, C, Shields-Argelès C, 2012. European and American perspectives on the meaning of natural. Appetite 59:448-55.

Rozin P, Spranca M, Krieger Z, Neuhaus R, Surillo D, Swerdlin A, Wood K, 2004. Preference for natural: instrumental and ideational/moral motivations, and the contrast between foods and medicines. Appetite 43:147-54.

SPSS, 2013. IBM Corporation. IBM SPSS
Statistics for Windows, version 22.0. IBM Corp., Armonk, NY, USA.

Stanziani A, 2008. Defining "natural product" between public health and business, 17 th to 21 st centuries. Appetite 51:15-7.

Wartella E, Rideout V, Zupancic H, Beaudoin-Ryan L, Lauricella A, 2015. Teens, health, and technology. A national survey (June 2015). Center on Media and Human Development School of Communication, Northwestern University, Chicago, IL, USA.

Yeung RMW, Morris J, 2001. Food safety risk: consumer perception and purchase behavior. Brit Food J 103:170-87. 